\title{
Does Design Contribute to Ease of Use: An exploratory study of Web Facets in The Result Pages of Two Search Engines
}

\author{
Elizabeth Milonas \\ Long Island University \\ Brookville, New York \\ emilonas@citytech.cuny.edu
}

\begin{abstract}
An exploratory study was conduced to examine the design aspects of Web facets found in the search result pages of two search engines: Exalead and Excite. The goal of the study was to determine if Web facet design could contribute to perceived ease of use. This study builds upon findings from an earlier study (Milonas, 2010) in which the results indicated that users perceived the Web facets evident in the search result pages of the Exalead search engine easier to use than those found in Excite. The researcher surmised that the design of these Web facets might have contributed to the difference in perceived ease of use. The relationship between design and user perception in determining the ease of use of Web facets within these two search engines is explored. In the first component of the study, an expert inspection of the various design aspects of the search result pages of Exalead and Excite was conducted. The aspects examined were: perceptual, learning, organizational and social. In the second part of the study, five participants conducted an experiment using the Web facets found in the search result pages of the two search engines. Findings of both the expert inspection and the usability evaluation showed that there does not seem to be a significant difference in the design of Web facets within the two search engines. The findings seem to indicate that design of Web facets is not a contributory factor in terms of Web facet ease of use.
\end{abstract}

\section{Keywords}

Web Facets, Search Engines, Interfaces, HCI.

This is the space reserved for copyright notices.

Advances in Classification Research, 2012, October 26, 2012, Baltimore, MD, USA.

Copyright notice continues right here.

\subsection{INTRODUCTION}

The World Wide Web consists of a plethora of information that a Web searcher can retrieve via search engines. A Web searcher submits a search query that once successfully executed, yields information within the search engine result page (SERP) in multi-page linear format. The SERP can be daunting due to the enormity of information returned which may or may not be relevant to the original search query. The searcher must make sense of the information returned and determine if the results satisfy the original search query or if further exploration is needed. Categories and Web facets are two methods provided by search engines and used by the searcher to expand, narrow or explore the original search query.

\subsection{Categories}

Categories provide the searcher with the means of organizing the search results by presenting a list of files, documents and links that possess the property of the category selected (Figure 1).

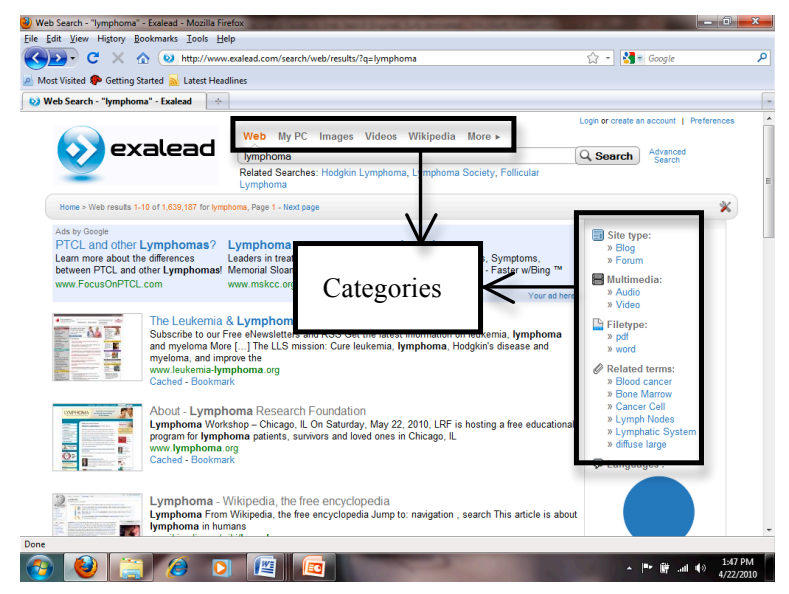

Figure 1. Categories found in the search engine Exalead.

The Web searcher is able to organize the results list by category, for example, the searcher can choose the category "Filetype" and sub-category "pdf" to display only PDF files related to the search term "Lymphoma" (Figure 2). 


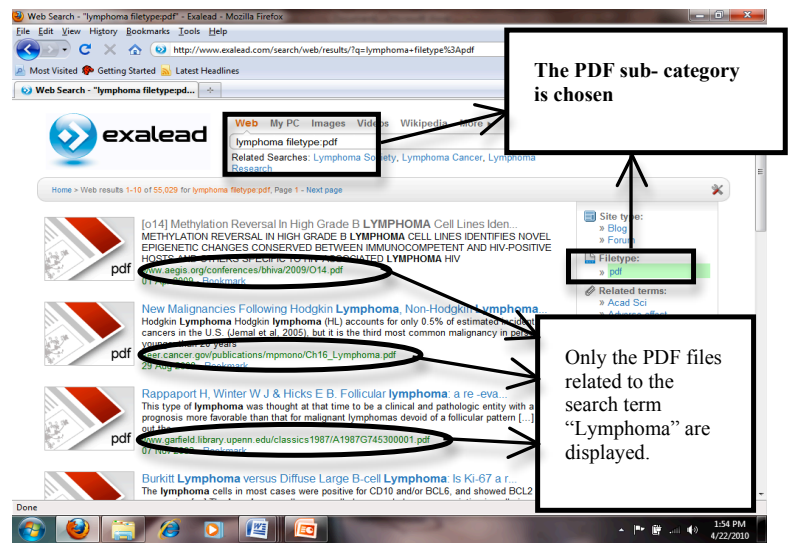

Figure 2. Using the "Filetype" Category

\subsection{Web Facets}

The second method used by search engines to expand, narrow or explore a search topic is Web facets. Web facets display the search results by different aspects of the search topic. For example, when searching for the topic "Lymphoma" using the Google search engine, Web facets related to the search topic are displayed. These Web facets present different aspects of the search topic such as "Lymphoma Symptoms" and "Lymphoma treatment" (Figure 3).

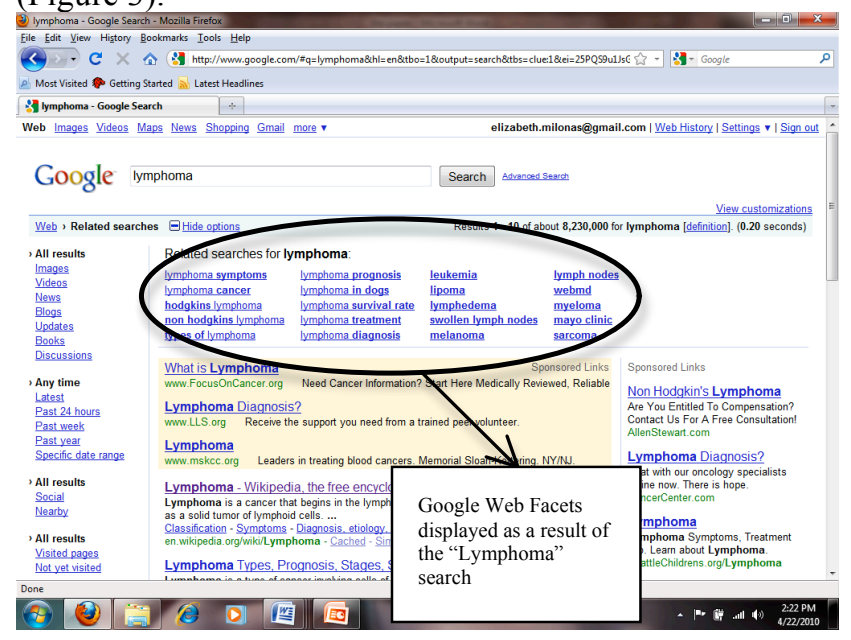

Figure 3: Google Web facets associated with the search topic "Lymphoma"

The searcher can then choose one of the Web facets listed to narrow, expand or explore the search topic further. In Figure 4, the searcher has chosen the Web facet "Lymphoma Symptoms" narrowing the search topic to information related to symptoms.

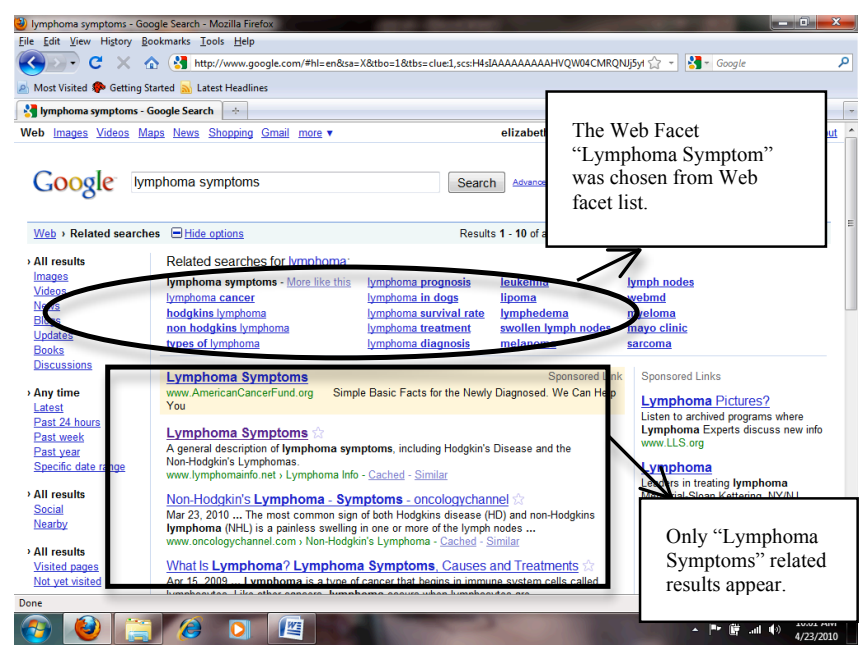

Figure 4. Using Web facets to narrow original search.

Within the search engine result pages, Web facets are evident under the headings of "Related Searches," "Also Try," or "Are you looking for."

\subsection{TRADITIONAL FACETS}

S.R. Ranganathan introduced the concept of facets in the early 1900s with his Colon Classification. According to Ranganathan $(1962,81)$, facets are the fiber that makeup a topic or subject and they are used to display the various dimensions (Shera \& Egan 1951, 99) of a topic or subject. Facets are the manifestations of five fundamental categories: personality, matter, energy, space, and time PMEST $(1951,101)$. Facets have been used extensively and with great benefit in the Library and Information Science domain where they were initially used in print media (Broughton, 2006) and later became instrumental within digital libraries. Recently the use of facets has become prevalent (Milonas, 2010) in e-commerce Websites. Many benefits have been realized in Website design (LaBarre, 2006) as well in the organization and navigation of Website information. Facets help users navigate through Web information easily (Hearst, 2008). Facets partition the information and provide alternative views (Zhang \& Marchionini, 2005) to users who require quick access to the information. Research has shown that the implementation of facets in Website information retrieval is beneficial to Web searchers especially to those who are unfamiliar (Yee et al., 2003; Kules, Kustanowitz \& Shneiderman, 2006; Capra et al., 2007) with the search topic. Facets provide a greater flexibility in navigating through the search results (Kules \& Shneiderman, 2008).

Web facets have similar properties to traditional facets in that they can present different aspects of the search topic ultimately guiding the searcher in alternate paths of discovery. Web facets are a relatively new concept and to the best of the author's knowledge, there are no substantial studies that have addressed the benefits associated with Web facets within the SERP. 
Milonas, E. (2013). Does Design Contribute to Ease of Use: An Exploratory Study of Web Facets in The Result Pages of Two Search Engines. Advances In Classification Research Online, 23(1), 62-65. doi:10.7152/acro.v23i1.14606

\subsection{STUDY}

The goal of this exploratory study was to examine the design aspects of Web facets in the SERP of two search engines: Exalead and Excite. The relationship between design and user perception in determining Web facet ease of use is explored. In the first component of the study, an expert inspection of the various design aspects of the search result pages of Exalead and Excite was conducted. The aspects examined were: perceptual, learning, organizational and social. In the second part of the study, an experiment was performed using five subjects. These subjects conducted two searches using Exalead and Excite. The five subjects completed a questionnaire and the results were analyzed.

\subsection{CONCLUSION}

Data from an earlier study (Milonas, 2010) was examined and the results of the t-test analysis showed that study participants who used Web facets in the Exalead search result page found these Web facets easier to use than those found in the Excite search result page. It was the belief of the researcher that the design of Web facets contributes to the ease of use of the Web facet. A study was conducted in which expert inspection and usability evaluations were used to examine design aspects in the search result pages of Exalead and Excite. The results from the expert inspection showed that both the Exalead and the Excite search engines utilize many aspects of design including perceptual, learning, organizational and social. The results from the usability evaluation conducted showed similar findings. The results of these two investigations showed that both search engines employed a full range of the design aspects and that the Exalead search engine did not incorporate significantly more design aspects than the Excite search engine. As a result, contrary to the researcher's belief and based on the results of this study, the design of Web facets within the search result page is not a contributory factor to the ease of use of the Web facets. The small number of participants who participated in this study may have had an impact on the outcome of the study. A future study will be conducted with a larger group of participants and the results from the two studies will be compared to determine if design aspects contribute to ease of use of Web facets. In addition, further investigation into other factors that may play a role in the ease of use of Web facets will be conducted. One such factor is the meaningfulness of Web facet terms used in the Exalead search result page. A future study will also be conducted to explore the concept of term meaning as a possible contributory factor.

\section{ACKNOWLEDGMENTS}

The author would like to thank Dr. Richard Smiraglia for his constant guidance and support and for his valuable suggestions.

\section{REFERENCES}

Broughton, V. (2006). The need for faceted classification as the basis of all methods of information retrieval. ASLIB Proceedings New Information Perspectives 58, 49-72.

Capra, R., Marchionini, G., Oh, J.S., Stutzman, F., \& Zhang, Y. (2007) Effects of structure and interaction style on distinct search tasks. Joint Conference on Digital Libraries - JCDL (Vancouver: ACM and IEEE), pp. 44251 .

Carroll, J.M. (2003). HCI Models Theories, and Frameworks: Toward a Multidisciplinary Science. San Francisco: The Morgan Kaufman Series in Interactive Technologies.

Chen, H. \& Dumais, S. (2000). Bringing order to the Web: Automatically categorizing search results. Proceedings of the ACM SIG/CHI Conference on Human Factors in Computing Systems (CHI’00), pp. 145-52.

Hearst, M.A. (2008). UIs for faceted navigation recent advances and remaining open problems. In Workshop on Computer Interaction and Information Retrieval, HCIR (October 2008) Redmond, WA.

Khalid, H.M. (2006). Embracing diversity in user needs for affective design. Applied Ergonomics 37, 409-18.

Kules, B. \& Shneiderman, B. (2004). Categorized graphical overviews for Web search results: An exploratory study using U.S. government agencies as a meaningful and stable structure. In Proceedings of the Third Annual Workshop on HCI Research in MIS, Washington D.C., December 10-11.

Kules, B., Kustanowitz, J., \& Shneiderman, B. (2006). Categorizing Web search results into meaningful and stable categories using fast-feature techniques. In Joint Conference on Digital Libraries - JCDL (North Carolina: $A C M$ and IEEE).

Kules, B., \& Shneiderman, B. (2008). Users can change their Web search tactics: design guidelines for categorized overviews. Information Processing and Management 44, 463-84.

La Barre, K. (2006). The use of faceted analytic-synthetic theory as revealed in the practice of Website construction and design. Submitted in partial fulfillment of the requirements of the degree Doctor of Philosophy in the School of Library and Information Science Indiana University.

Mat-Hassan, M., \& Levene, M. (2001). Can navigational assistance improve search experience: A user study. First Monday 6.

Milonas, E. (2010). The use of facets in Web search engines. In Gnoli, Claudio and Mazzochi, Fulvio, (Eds.), Paradigms and Conceptual Systems in Knowledge Organization, Proceedings of the $11^{\text {th }}$ International ISKO Conference, 23-26 February 2010, Rome Italy. Advance 
in Knowledge Organization v. 12. Würzburg: Ergon Verlag, 2010, pp. 349-55.

Ranganathan, S.R. (1962). Elements of Library Classification. India: Asia Publishing House.

Shera, J.H. \& Egan, M.E. (Eds.) (1951). Bibliographic Organizations. Chicago: The University of Chicago Press.

Xie, H. (2002). Supporting ease-f-use and user control: desired features and structures of Web-based online IR systems. Information Processing and Management 39, 899-922.

Yanbe, Y., Jatowt, A., Nakmura, S., \& Tanka, K. (2007) Towards improving Web search by utilizing social bookmarks. In Proceedings of the 7th International Conference on Web Engineering (ICWE 2007).

Yee, K., Swearingen, K., Li, K., \& Hearst, M. (2003). Faceted metadata for image search and browsing. In Proceedings of the 2003 Conference on Human Factors in Computing System - CHI '03 (New York: ACM) pp. 401-8.

Zhang, J. \& Marchionini, G. (2005). Evaluation and evolution of a browse and search interface: Relation Browser++. In Proceedings of the 2005 National Conference on Digital Government Research. Atlanta: Digital Government Society of North America, pp. 17988 . 